\title{
latrogenic implantation of myxoid dedifferentiated chondrosarcoma at donor site: A case report and review of literature
}

\begin{abstract}
latrogenic implantation of chondrosarcoma (CS) is not only extremely rare but also technically avoidable and impacts with morbidity, mortality, and quality of life (QoL). We report a similar case of myxoid dedifferentiated CS at remote tissue-graft donor site (left chest-wall pectoralis major myocutaneous flap). Although the exact mechanism of primary tumor cells seeding is not clear, the probable causes are direct contamination from surgical instruments and altered blood circulation at the graft-donor site.
\end{abstract}

Keywords: Chondrosarcoma, latrogenic implantation, quality of life

\section{INTRODUCTION}

latrogenic implantation of chondrosarcoma (CS) to the remote uninvolved tissue-graft donor site is extremely rare, although incidences involving the other tumor histopathological subtypes are not uncommon in the literature. It not only poses a challenge to the repeat salvage surgery but also affects the cause-specific survival and quality of life of the patient. The most common sites involved are generally the skin and bones. ${ }^{[1-5]}$ However, the exact mechanism of seeding of the primary tumor to graft donor site is unclear and controversial. It is quite possible that such tumor seeding may happen due to poor surgical technique violating the principles of tumor surgery allowing direct transfer of viable tumor cells from the primary site to the donor site or it may result from hematogenous transfer.

The below-mentioned case report highlights regarding the very unusual appearance of CS within the surgical scar of graft donor site suggesting a possible iatrogenic tumor implantation during the reconstructive surgery.

\section{CASE REPORT}

A 44-year young man, nontobacco addict and without any comorbidities, presented to our department with a

\begin{tabular}{|l|c|}
\hline \multicolumn{2}{|c|}{ Access this article online } \\
\hline \multirow{2}{*}{ Website: } & Quick Response Code \\
www.asjo.in & 四 \\
\hline \multirow{2}{*}{ DOI: } & \\
10.4103/ASJO.ASJO_86_16 & \\
&
\end{tabular}

painful and progressive swelling on the surgical scar site of the left chest wall for the past one month [Figure 1]. There were no other complaints apart from the above. Six months before, he was diagnosed with CS of the left retromolar trigone (RMT) for which he had undergone a left composite dissection (wide local excision with left hemimandibulectomy) and left-modified neck dissection with immediate reconstruction using pectoralis major myocutaneous (PMMC) flap graft harvested from the left chest in some other hospital. The postoperative histopathology and the immunohistochemistry were consistent with myxoid dedifferentiated CS [Figure 2a] with primary at the left RMT area. The primary tumor size was $4 \mathrm{~cm} \times 3.5 \mathrm{~cm}$ with a depth of invasion of $1 \mathrm{~cm}$ with uninvolved underlying mandibular bone and free resected margins (closest margin of $1.2 \mathrm{~cm}$ along the posteromedial aspect of the tumor).

\section{Chira Ranjan Khadanga, Jagadishwar Goud GAJAGOWNI ${ }^{1}$}

Departments of Radiation Oncology and ${ }^{1}$ Surgical Oncology, Krishna Institute of Medical Sciences, Hyderabad, Telangana, India

Address for correspondence: Dr. Chira Ranjan Khadanga, Department of Radiation Oncology, Krishna Institute of Medical Sciences, Hyderabad - 500 003, Telangana, India.

E-mail: dr.crk88@gmail.com

This is an open access journal, and articles are distributed under the terms of the Creative Commons Attribution-NonCommercial-ShareAlike 4.0 License, which allows others to remix, tweak, and build upon the work non-commercially, as long as appropriate credit is given and the new creations are licensed under the identical terms.

For reprints contact: reprints@medknow.com

How to cite this article: Khadanga CR, Gajagowni JG. Iatrogenic implantation of myxoid dedifferentiated chondrosarcoma at donor site: A case report and review of literature. Asian J Oncol 2018;4:17-20. 
Lymphovascular space invasion or any perineural invasion was not seen. Eight lymph nodes dissected were free of tumor. The final pathological stage was $\mathrm{pT}_{1 \text { bp }} \mathrm{N}_{0} \mathrm{M}_{0}$, Grade-III, Stage-IIA (AJCC $7^{\text {th }}$ ). Postoperative adjuvant radiation therapy (RT) to the tumor bed and ipsilateral neck to a dose of $50 \mathrm{~Gy} / 25$ fractions/35 days (from March 18, 2015, to March $23,2015)$ was given.

The patient presented to our center 7 months later with a solid-cystic mass on the surgical scar on the left chest wall corresponding with the PMMC flap donor site [Figure 1] approximately $4 \mathrm{~cm} \times 4 \mathrm{~cm}$ size, immobile, tender, and without any restriction of left shoulder movement or any distal neurovascular deficit at left upper limb. Rest of the primary postoperative site as well as the neck was normal. Fine-needle aspiration cytology from the above lesion was suggestive of recurrent poorly differentiated CS. Metastatic workup was done with a ${ }^{18}$ fluorodeoxy glucose positron emission tomography-computed tomography, which was showing a mass of $42 \mathrm{~mm} \times 31 \mathrm{~mm}$ with fluoro-2-deoxy-D-glucose avidity $\left(\mathrm{SUV}_{\max } 5\right)$ at the same anatomical site [Figure 3] as on the clinical examination with no other area involvement. Subsequently, he underwent a wide local excision of the above lesion. The histopathology was myxoid dedifferentiated CS [Figure 2b] with negative deep margin as well as surrounding margins, closely resembling with the primary histopathology. He also received postoperative adjuvant $\mathrm{RT}$ to the tumor-bed with adequate margin to a dose of $60 \mathrm{~Gy} / 30$ fractions/43 days using $6 \mathrm{MeV}$ electrons prescribed at the maximum depth. He well tolerated all the treatments with good compliance and without any treatment gap. The observed maximum acute RT toxicity was Radiation Therapy Oncology Group (RTOG) grade-II at the left axillary folds which were managed conservatively, and the patient recovered well.

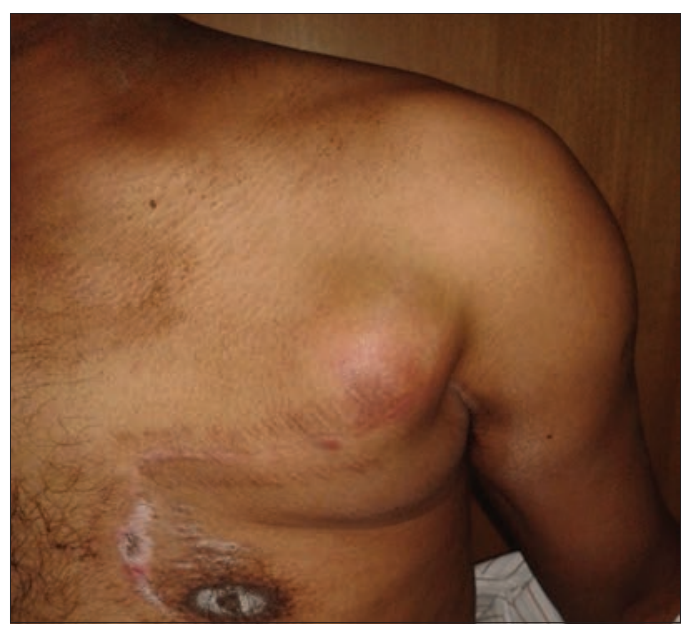

Figure 1: Swelling on the left chest wall scar (pectoralis major myocutaneous donor site). Scar of previous surgery of left neck is also seen

\section{DISCUSSION}

Iatrogenic implantation of the tumor cells at the graft harvest site is an avoidable complication. This not only poses a challenge to a salvageable surgical excision but also adds on to existing morbidity and even mortality in malignant tumors. Furthermore, it deeply impacts the psychological, financial, and legal implications.

CS is more common in older adults but can occur at any site of the body. Although the pelvis and chest wall are the most common sites, it is also seen in the head and neck region, consisting approximately $0.1 \%$ of the all malignant tumors of this region. ${ }^{[6]}$ The majority $(80 \%-85 \%)$ are conventional CS, and the rest (15\%-20\%) are of clear cell, dedifferentiated, myxoid, and mesenchymal subtypes..$^{17,8]}$ Among the above, dedifferentiated CS not only a rare histologic variant but also rarely originates in head and neck region with a high probability of local recurrence. ${ }^{[9]}$ Till now, the contemporary standard of care is adequate surgical resection. However, adjuvant RT can be given in incomplete excision. ${ }^{[10]}$ It has also shown a high chance of recurrence as well as distant metastasis at any time ranging from a few months to several years posttreatment. ${ }^{[11]}$ Local recurrences are quite frequent accounting for $20 \%-60 \%$ of the cases. Approximately $20 \%$ of tumors metastasize predominantly to the lungs.

Our patient developed an isolated recurrence at the scar of the left PMMC donor-site within 7 months postsurgery. The chest wall or axilla has not been shown to be a site for recurrence in CS at head and neck as per the different literature survey. Hence, the above conditions hint toward an iatrogenic and neither a synchronous (simultaneous multifocal primary tumors) nor a metachronous (appearance of de novo similar lesion after removal from another site) lesion. Iatrogenic tumor implantations were first described by Ryall in 1907, believing that some recurrent tumors were due to contaminated surgical instruments with cancer cells. ${ }^{[12]}$ The exact mechanism of seeding of the primary tumor to graft donor site is not clear. Although direct contamination by viable tumor cells presents on gloves and surgical instruments while performing the definitive operation and harvesting

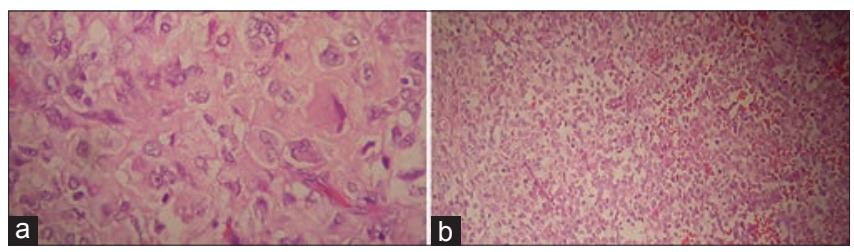

Figure 2: (a) Sections from primary tumor show undifferentiated tumor cells with polygonal cell vesicular nuclei and prominent nucleoli ( $H$ and $E$, $\times 400)$. (b) Implantation tumor show undifferentiated tumor cells with focal chondroid matrix ( $H$ and $E, \times 200)$ 

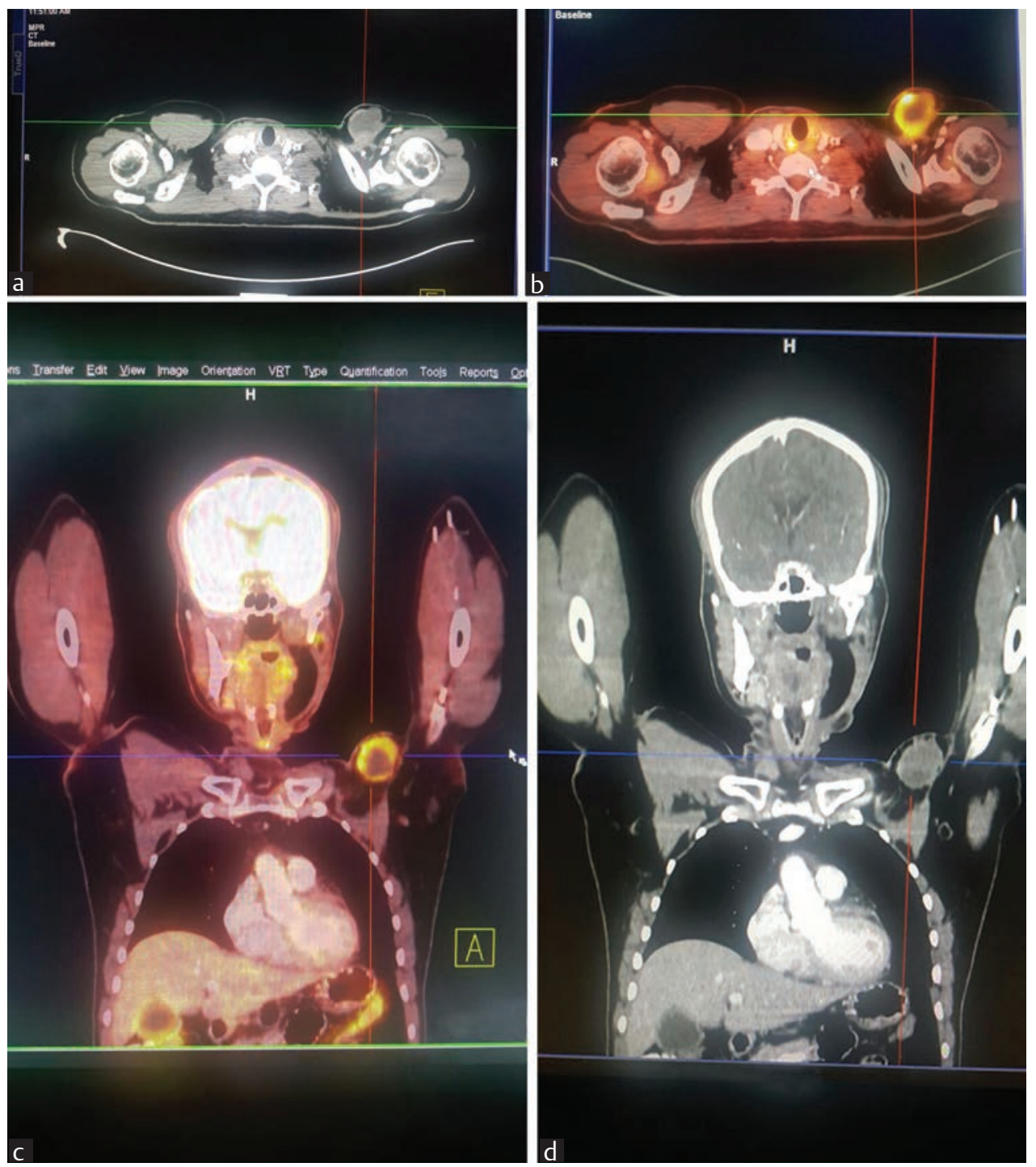

Figure 3: (a) Contrast-enhanced computed tomography thorax showing solid-cystic mass at left chest wall. (b) 18Fluorodeoxy glucose positron emission tomography-computed tomography showing fluorodeoxy glucose-avid mass at left chest wall. (c) 18Fluorodeoxy glucose positron emission tomographycomputed tomography showing solid-cystic mass at left chest wall. (d) Contrast-enhanced computed tomography thorax showing solid-cystic mass at the left chest wall

autologous graft at the same sitting is most likely, however, it can be attributed to altered circulation at the healing donor site. There is some theoretical and experimental evidence that surgical trauma predisposes to the localization of tumor cells. Various theories supporting this include more circulating tumor cells with manipulation of primary tumor increased adherence of tumor cells to damaged endothelium of the microcirculation, and alteration of blood flow or coagulation mechanism in the traumatized graft harvesting site. ${ }^{[13-16]}$

\section{CONCLUSION}

Iatrogenic implantation of head and neck myxoid dedifferentiated CS at left PMMC donor site is both technically avoidable and questionable salvageability. It also deeply impacts with the morbidity, mortality, and quality of life. Adopting a proper technique of tumor surgery will potentially avoid this situation.

\section{Declaration of patient consent}

The authors certify that they have obtained all appropriate patient consent forms. In the form the patient(s) has/have given his/her/their consent for his/her/their images and other clinical information to be reported in the journal. The patients understand that their names and initials will not be published and due efforts will be made to conceal their identity, but anonymity cannot be guaranteed.

\section{Financial support and sponsorship}

Nil. 


\section{Conflicts of interest}

There are no conflicts of interest.

\section{REFERENCES}

1. Cole GW Jr., Sindelar WF. Iatrogenic transplantation of osteosarcoma. South Med J 1995;88:485-8.

2. Kroll SS, Tavollali M, Castello-Sendra J, Pollock RE. Risk of dissemination of cancer to flap donor sites during immediate reconstructive surgery. Ann Plast Surg 1994;33:573-5.

3. Flook D, Horgan K, Taylor BA, Hughes LE. Surgery for malignant melanoma: From which limb should the graft be taken? Br J Surg 1986;73:793-5.

4. Martin-Oliva X, Ballart-Gavila C, Fernandez-Suarez M, Navarro-Farre B, Valdes-del-Molino AP. Metastasis of an ameloblastoma to the iliac crest. Int Orthop 1994;18:50-2.

5. Yip KM, Lin J, Kumta SM. A pelvic osteosarcoma with metastasis to the donor site of the bone graft. A case report. Int Orthop 1996;20:389-91.

6. Chowdhury A, Kalsotra P, Bhagat DR, Sharma P, Katoch P. Chondrosarcoma of the maxilla-recurrent. JK Sci 2008;10:94-6.

7. Gelderblom H, Hogendoom PC, Dijkstra SD, van Rijswijk CS, Krol AD, Taminiau AH, et al. The clinical approach towards chondrosarcoma. Oncologist 2008;13:320-9.
8. Meijer D, de Jong D, Pansuriya TC, van den Akker BE, Picci P, Szuhai K, et al. Genetic characterization of mesenchymal, clear cell, and dedifferentiated chondrosarcoma. Genes Chromosomes Cancer 2012;51:899-909.

9. Antonescu CR, Argani P, Erlandson RA, Healey JH, Ladanyi M, Huvos AG, et al. Skeletal and extraskeletal myxoid chondrosarcoma: A comparative clinicopathologic, ultrastructural, and molecular study. Cancer 1998;83:1504-21.

10. Garrington GE, Collett WK. Chondrosarcoma I. A selected literature review. J Oral Pathol 1988;17:1-11.

11. Lone SA, Sajad M, Lateef M. Chondrosarcoma of the paranasal sinuses. JK Sci 2003;5:124-5.

12. Ryall C. Cancer infection and cancer recurrences: A danger to avoid in cancer operations. Lancet 1907;2:1311-6.

13. Ferguson PC, Sommerville S, Grimer RJ. Possible metastasis of osteosarcoma to a remote biopsy site: A case report. Clin Orthop Relat Res 2004;424:216-20.

14. Fisher B, Fisher ER, Feduska N. Trauma and the localization of tumor cells. Cancer 1967;20:23-30.

15. Murthy SM, Goldschmidt RA, Rao LN, Ammirati M, Buchmann T, Scanlon EF, et al. The influence of surgical trauma on experimental metastasis. Cancer 1989;64:2035-44.

16. Alexander JW, Altemeier WA. Susceptibility of injured tissues to hematogenous metastases: An experimental study. Ann Surg 1964;159:933-44. 